\title{
Mulheres-Maravilhas, as Capitãs Contemporâneas?
}

DOI: http://dx.doi.org/10.21165/el.v49i2.2692

\section{Luciane de Paula' \\ Luana Maria Gava²}

\section{Resumo}

Este artigo se propõe a pensar a constituição das super-heroínas Mulher-Maravilha e Capitã Marvel e suas funções sociais no momento sócio-histórico contemporâneo. A fundamentação teórica se calca nas concepções bakhtinianas de dialogia, sujeito, voz social, enunciado e linguagem, bem como em estudos sobre a mulher e sobre superheróis. O objetivo é entender como a mulher é representada nos dois filmes, o que significa ser super-heroína e, se é possível, de fato, considerar ou não as protagonistas modelos de empoderamento feminino. A hipótese é a de que os sujeitos das obras refletem e refratam vozes sociais sobre ser mulher, com comportamentos que atendem necessidades de mercado e corroboram com estereótipos. Metodologicamente, a proposta utiliza a dialética-dialógica, calcada na construção histórica dos sujeitos, em cotejo com outros enunciados. A justificativa se volta à função social desses ícones.

Palavras-chave: estudos bakhtinianos; mulher; vozes sociais; linguagem; verbivocovisualidade.

1 Universidade Estadual Paulista "Júlio de Mesquita Filho" (UNESP), Assis, São Paulo, Brasil; lucianedepaula1@gmail.com; https://orcid.org/0000-0003-1727-0376

2 Universidade Estadual Paulista "Júlio de Mesquita Filho" (UNESP), Araraquara, São Paulo, Brasil; luanagava23@gmail.com; https://orcid.org/0000-0002-9616-2746 


\title{
Wonder Women, The Contemporary Captains?
}

\begin{abstract}
This article aims to think about the constitution of the superheroes Wonder Woman and Captain Marvel and their social functions in the contemporary socio-historical moment. The theoretical foundation is based on Bakhtinian conceptions of dialogue, subject, social voice, utterance and language, as well as studies on women and superheroes. The goal is to understand how women are portrayed in both movies, what it means to be a superhero, and whether it is possible, in fact, to consider the protagonists as models of female empowerment or not. The hypothesis is that the subjects of the works reflect and refract social voices about being a woman, with behaviors that meet market needs and corroborate with stereotypes. Methodologically, the proposal uses the dialectic-dialogic, based on the historical construction of the subjects, in comparison with other statements. The justification turns to the social function of these icons.
\end{abstract}

Keywords: bakhtinian studies; woman; social voices; language; verbivocovuality.

\section{Era uma vez uma amazona e uma humana icônicas}

Este artigo propõe uma reflexão acerca de dois ícones de empoderamento feminino, dos quadrinhos às telas de cinema: a Mulher-Maravilha (2017) e a Capitã Marvel (2019). As duas heroínas representam imagens de mulher que servem como inspiração para as meninas e mulheres no mundo todo por salvarem o mundo do mal, de maneiras diferentes: a Mulher-Maravilha (MM), com a ajuda de seu amor, Steve Trevor; e a Capitã Marvel (CM), com o auxílio de seus amigos.

Com as discussões feministas em destaque nessa nova onda contemporânea, as superheroínas ganharam evidência. Em 2016, a MM aparece em Batman vs. Superman, dos estúdios Warner Bros, em parceria com a DC Comics; no ano seguinte, ela ganha seu primeiro filme solo e este obteve tanto sucesso que já está sendo gravado o segundo filme, com previsão de estreia para 2020. A maior concorrente da DC, a Marvel, vendo o sucesso de bilheteria de MM, criou a CM, versão feminina do Capitão Marvel, que havia morrido nos quadrinhos e CM também ganhou o primeiro filme solo (o primeiro de uma super-heroína da empresa) em 2019, com possibilidade de continuação.

O objetivo deste trabalho é entender como a mulher é representada nas duas produções fílmicas e se é possível considerá-las ícones de empoderamento feminino ou não. A hipótese é de que elas refletem e refratam vozes sociais sobre o que é ser mulher, muitas vezes, de forma estereotipada, uma vez que criadas numa sociedade patriarcal. 
A Análise Dialógica do Discurso fundamenta as reflexões empreendidas. Conceitos como signo ideológico, enunciado, sujeito, voz social, dialogia e linguagem ancoram as análises. O método adotado é a dialética-dialógica, assim denominado por Paula, Figueiredo e Paula (2011) e em consonância com os estudos bakhtinianos, que consideram o cotejo como constitutivo. O procedimento consiste em três etapas, relacionadas entre si: descrição, análise e interpretação dos enunciados.

A importância desta reflexão se justifica pela relevância social das imagens de mulher veiculadas pelas personagens, uma vez que elas saem das telas do cinema e estampam produtos de consumo, viram fantasias infantis, temas de aniversário e servem como inspiração para muitas pessoas. Os valores incutidos nas super-heroínas ultrapassam a ficção e circulam, como ícones de vida. Sendo assim, discutir sobre esse processo é essencial porque as personagens se tornaram modelos de mulher, especialmente a Mulher-Maravilha, com sua imagem veiculada no dia internacional da mulher e sua "personalidade" tomada como embaixadora da ONU no final de outubro de 2016 ("demitida do cargo" dois meses depois por ser criticada por grupos de ativistas do mundo todo), entendida como "símbolo da paz, justiça e igualdade" (sua imagem "seria usada na campanha anual de promoção aos direitos de meninas e mulheres pelo mundo" ${ }^{3}$ ). A Capitã Marvel, por sua vez, antes de assumir essa identidade (em 2012), que a consolidou como ícone feminista da cultura pop, passou por diversos nomes e papéis desde o seu nascimento, nos anos 60: Ms. Marvel e Binária, por exemplo. Refletir sobre esses ícones que nós, mulheres, adotamos ou que nos é incutido como poderoso ou não é o que esse artigo pretende fazer.

\section{Estudos bakhtinianos: a fundamentação das reflexões}

O Círculo de Bakhtin, formado por componentes de diversas áreas do conhecimento, existiu do início do século XX até 1975. Os três integrantes aos quais temos mais acesso e pautamos nossas reflexões são Volóchinov, Medviédev e Bakhtin. Em geral, seus escritos se voltam à linguagem e a toda a sua complexidade. Mesmo tendo a especificidade da linguagem verbal e, mais particularmente, obras pautadas no discurso romanesco, há diversos momentos e incursões sobre a linguagem de maneira ampla, com observações explícitas sobre a semiose visual e a musical (como ocorre em Marxismo e Filosofia da Linguagem, Estética da Criação Verbal e Problemas da Obra de Dostoiévski, por exemplo, de maneira mais incisiva).

O Círculo concebe a linguagem como social e histórica, materializada em um enunciado (concreto) situado, produzida por um sujeito em determinado tempo e espaço, repleta de vozes sociais, em um constante diálogo (embate).

3 Fonte: Veja Digital. Disponível em: https://veja.abril.com.br/mundo/mulher-maravilha-e-cortadade-cargo-de-embaixadora-da-onu/. Acesso em: 15 set. 2019. 
A definição de signo ideológico é explicitada por Volóchinov, em sua obra Marxismo e filosofia da linguagem (2017) e por Medviédev, n'O Método Formal nos Estudos Literários (2012). Volóchinov (2017, p. 92) afırma que tudo que é ideológico possui uma significação representada marcada num signo e é nesse sentido que afirma que "todo signo é ideológico", pois explica ele que:

[...] qualquer corpo físico pode ser percebido como a imagem de algo; por exemplo, como a encarnação, nesse objeto único, da estagnação e da necessidade da natureza. Essa imagem artístico-simbólica de um objeto físico já é um produto ideológico. O objeto físico é transformado em um signo. Sem deixar de ser uma parte da realidade material, esse objeto, em certa medida, passa a refratar e a refletir outra realidade.

Neste artigo, tomamos a noção de mulher como signo ideológico que reflete e refrata uma ideia de sujeito com valores acerca do ser-mulher. Esse signo é atravessado por vozes sociais que expressam valores axiológicos que, de certa forma, podem constituir nosso tempo e espaço. Diante disso, questionamentos como "O que é ser mulher?" e "o que é ser super-heroína?" são perguntas sem respostas exatas, pois essas concepções variam de acordo com o sujeito que as responde. Aqui, pretendemos refletir acerca dos valores que constituem o ser Mulher-Maravilha e o ser Capitã Marvel, tomados como ícones de empoderamento ou do ser-mulher na contemporaneidade.

Para o caso da heroína da Warner Bros, em parceria com a DC Comics, o adjetivo "maravilha", que compõe o nome de MM, coaduna com características da personagem, como guerreira, forte, independente, questionadora, subversiva, apaixonada, uma mulher que usa seus poderes para seguir um homem e abre mão de sua vida de amazona em nome do seu amor por Steve Trevor. Nesse sentido, qual seria a diferença dos valores que constituem a ideia de "princesa" como uma mulher frágil, dependente, à espera do "beijo do amor verdadeiro", submissas, sem vida própria a não ser o casamento com "final feliz"? Da mesma forma, a heroína da Marvel, Carol Danvers, ganha uma patente militar (de capitã) e deixa de ser uma identidade própria ao passar a ser chamada pelo nome da empresa que a criou (Marvel), como versão feminina de um símbolo masculino da empresa e da cultura norte-americana (o Capitão Marvel). Questionamos, nesse caso, o que adianta lutar pela igualdade de gêneros como ela faz, salvar o planeta do mal, mas como símbolo de uma nação super-poderosa, exploradora e militarizada? Essas contradições que compõem os dois sujeitos em questão pautam nossas reflexões. Volóchinov (2017, p. 93) afırma que "as categorias de avaliação ideológica (falso, verdadeiro, correto, justo, bom etc.) podem ser aplicadas a qualquer signo", então, tudo depende do ponto de vista de que olhamos. O fato de MM e CM serem guerreiras e donas de si, poderosas por um lado, não exclui outras facetas que as constituem como frágeis, de certa forma, ingênuas ou militares, por outro. 
O enunciado é, ao mesmo tempo, único/singular, situado e elo na cadeia discursiva. Único porque, mesmo que se repita a mesma palavra várias vezes, ela será diferente a cada momento em que for entoada. Situado porque acontece em determinado tempo e espaço históricos - e essa contextualização deve ser considerada. E elo na cadeia discursiva porque um enunciado nunca está isolado, ele responde a outros, anteriores e futuros, relacionando-se a valores diversos (em concordância ou polêmica, seja aberta ou velada, como reflexo e refração simples ou dupla).

Os enunciados selecionados para este trabalho são respostas geradas pelos filmes das super-heroínas no Brasil, sendo alguns bem recentes e outros criados perto do lançamento do filme (esses foram os critérios metodológicos de delimitação do corpus). Contextualizamos quando e onde cada enunciado foi criado, circulou e foi recebido, pois as vozes sociais mudam de acordo com suas condições de produção. Volóchinov (2017, p. 184) afırma que o enunciado surge como resposta a outro anterior e que ele gera outras respostas depois de finalizado: "ele é apenas um elo na cadeia ininterrupta de discursos verbais". Além disso, todo enunciado "é orientado para ser percebido no contexto da vida científica ou da realidade literária atual, isto é, na formação daquela esfera ideológica da qual ele é um elemento indissolúvel" (VOLÓCHINOV, 2017, p. 185).

Para o Círculo, os sujeitos se constituem em sua relação de alteridade. Na relação com o outro, o sujeito se altera e sua identidade se constitui. Por sua vez, Geraldi (2010, p. 289290) afirma, em Círculo de Bakhtin: teoria inclassificável, que:

Deste movimento contínuo entre o eu e o outro, em que eu vivencio minha vida de dentro e o outro me dá completude do exterior, infere-se que os acabamentos ou as identidades serão sempre múltiplas no tempo e no espaço, pois a relação nunca é com somente um e mesmo outro e a vida não se resume a um e sempre mesmo tempo.

No caso dos sujeitos super-heroínas estudados, a relação de alteridade existente ocorre de diversas formas. No caso por nós estabelecido, procuramos apresentar um vínculo, tanto de uma personagem com a outra, quanto delas com os fãs/haters, conforme veremos com os exemplos discutidos.

Quanto ao dialogismo, uma das concepções mais abrangentes e fundamentais dos estudos bakhtinianos consiste na relação (que contempla concordâncias e discordâncias) entre discursos e sujeitos (sempre de linguagem). A interação social provoca embates de vozes sociais consonantes e destoantes. As relações dialógicas acontecem porque os sujeitos possuem posicionamentos axiológicos diferentes e produzem enunciados que respondem uns aos outros. Faraco (2009, p. 66), em seu livro Linguagem \& Diálogo: as ideias linguísticas do Círculo de Bakhtin, afirma que: 
Para haver relações dialógicas, é preciso que qualquer material linguístico (ou de qualquer outra materialidade semiótica) tenha entrado na esfera do discurso, tenha sido transformado num enunciado, tenha fixado a posição de um sujeito social. Só assim é possível responder (em sentido amplo e não apenas empírico do termo), isto é, fazer réplicas ao dito, confrontar posições, dar acolhida fervorosa à palavra do outro, confirmá-la ou rejeitá-la, buscar-lhe um sentido profundo, ampliá-la. Em suma, estabelecer com a palavra de outrem relações de sentido de determinada espécie, isto é, relações que geram significação responsivamente a partir do encontro de posições avaliativas.

Nos filmes aqui estudados, o dialogismo é peça fundamental. Isso porque as heroínas possuem seus posicionamentos bem marcados e lutam até o fim para defendê-los. Expressam seus valores pela linguagem (verbal, visual e entoativa), de modo que toda e qualquer produção ideológica acontece na e pela linguagem. Ademais, o Círculo de Bakhtin não considera apenas o verbal como linguagem, mas também o visual/imagético e o vocal/musical/sonoro. Paula (2017a, 2017b), que tem seus estudos voltados à produção do Círculo, denominou esse fenômeno como linguagem verbivocovisual ${ }^{4}$. 0 termo utilizado por ela é extemporâneo às obras bakhtinianas e não aparece utilizado pelo Círculo, pois se trata de uma metáfora advinda da poesia concreta, mas a concepção de linguagem se encontra na obra do Círculo como noção de linguagem.

Em Marxismo e filosofia da linguagem (2017), Volóchinov enfatiza a importância da linguagem ao longo de toda a obra. Ela está diretamente ligada ao signo ideológico, pois ele é a realização material da língua. $O$ autor explica que:

A lógica da consciência é a lógica da comunicação ideológica, da interação sígnica de uma coletividade. Se privarmos a consciência do seu conteúdo sígnico ideológico, não sobrará absolutamente nada nela. A consciência apenas pode alojar-se em uma imagem, palavra, gesto significante etc. Fora desse material resta um ato fisiológico puro, não iluminado pela consciência, isto é, não iluminado nem interpretado pelos signos. (VOLÓCHINOV, 2017, p. 98, grifos nossos).

Podemos notar, neste trecho, que as imagens e os gestos, além da palavra, também são considerados como linguagem. Por um lado, Volóchinov (2017, p. 98) defende que "a palavra é o fenômeno ideológico par excellence.". Por outro lado, explica que "uma palavra não pode transmitir adequadamente uma obra musical ou uma imagem da pintura." (VOLÓCHINOV, 2017, p. 101), e que, mesmo que esses signos ideológicos não possam ser transmitidos pela palavra (verbal), eles precisam dela para se apoiar.

4 A questão da verbivocovisualidade está em desenvolvimento, com alguns resultados já publicados em artigos assinados por Paula, sozinha e com coautores (2017a, 2017b, 2017c, 2019a, 2019b). 
Ainda sobre Volóchinov, ele tem um artigo todo dedicado a este assunto, chamado "Que é a linguagem?", que se encontra no livro A construção da enunciação e outros ensaios (2013). Nele, o autor explica a origem da linguagem como um instrumento para a interação social e fala da importância da entoação: "A mais simples expressão de fome: 'quero comer', pode ser pronunciada - expressa - somente numa determinada língua - ainda que seja a linguagem mímica - e será pronunciada com determinada entonação, com uma gesticulação determinada." (VOLÓCHINOV, 2013, p. 147). Sem a entoação, uma mesma palavra pode significar diversas coisas diferentes, a tal ponto que a dimensão verbal precisa da dimensão vocal para fazer sentido e isso fica claro com a exemplificação dada pelo autor acerca da expressão "Bem", no ensaio Discurso na vida e discurso na arte (Mimeo, s/d). Nesse sentido, para Paula (2017a, 2017b, 2017c, 2019a, 2019b), os estudos bakhtinianos se pautam em três dimensões de linguagem (a verbal, a entoativa/sonora e a visual), presentes em todos os enunciados, com mais ou menos intensidade, mesmo que apenas uma das dimensões esteja materializada de maneira explícita. Nas histórias em quadrinhos, por exemplo, apenas as dimensões verbal e visual se encontram concretizadas, mas a vocal está subentendida, já que as falas das personagens apresentam onomatopeias, exclamações, interrogações e entoações discursivas. Nos filmes, enunciados audiovisuais, a tridimensionalidade da linguagem é explorada ao máximo, dada a síncrese genérica constitutiva do audiovisual.

A defesa de Paula (2017a, 2017b, 2017c, 2019a, 2019b) para a concepção de verbivocovisualidade da linguagem como concepção bakhtiniana se pauta na argumentação utilizada pelo próprio Círculo acerca da "linguagem das linguagens" (o que se encontra explicitado por Volóchinov, 2017, 2013 e s/d; por Bakhtin, 1997 e 2003; e por Medviédev, 2012). Além disso, a estudiosa também considera a produção de outras obras do Círculo, como a relação de Problemas da obra de Beethoven, de Volócinov, publicada em 1926; com Problemas da Obra de Dostoiévski, de Bakhtin, de 1929; ambas produzidas em diálogo e tendo como foco noções advindas da música para a linguagem verbal, especificamente romanesca, como ocorre com o conceito de polifonia, por exemplo. Por fim, a pesquisadora considera ainda as materialidades enunciativas como expressões do que tem chamado de verbivocovisualidade. Calcadas nessa perspectiva, os enunciados apresentados neste artigo são analisados não apenas em sua materialidade (verbal, visual, sonora ou sincrética), mas em sua tridimensionalidade verbivocovisual.

\section{A maravilha da mulher-amazona e da mulher-capitã}

A Mulher-Maravilha é uma das mais conhecidas super-heroínas de todos os tempos. Ela foi criada em 1941 pela DC Comics, mesma empresa que criou Batman e Superman, e ganhou o mundo desde então. Atualmente, sua imagem continua em evidência, principalmente depois de seu aparecimento no filme Batman vs. Superman (2016) e do lançamento do seu próprio filme Mulher-Maravilha (2017), o primeiro filme solo de uma super-heroína a ganhar tanto reconhecimento ao redor do mundo. 
O longa-metragem, produzido pelos estúdios Warner Bros em parceria com a DC Comics, é bastante semelhante com a primeira aparição da heroína das histórias em quadrinhos (HQs). A narrativa começa com um avião caindo na ilha das amazonas, Themyscira; o homem é salvo por Diana, a Mulher-Maravilha, mas a ilha é invadida pelos alemães que perseguiam Steve Trevor, o homem salvo por MM que revela às amazonas ser um espião norte-americano infiltrado entre os nazistas. Então, um grande conflito acontece: as amazonas vencem, mas têm muitas perdas. A Mulher-Maravilha não aceita a ideia de que o mundo está em guerra e que milhões de inocentes são mortos; ela, então, decide levar Steve de volta para o mundo dos homens e ajudá-lo a salvar o planeta do mal, entendido por ela como algo encomendado pelos deuses.

O filme foi um sucesso, agradou a grande maioria do público e vendeu mais de 820 milhões de dólares em bilheteria, conquistando a posição de filme de super-herói mais lucrativo do ano. A atriz Gal Gadot recebeu elogios por parte da crítica e do público por sua atuação. A seguir, um dos primeiros cartazes do filme:

Figura 1. Cartaz de divulgação do filme Mulher-Maravilha (2017)

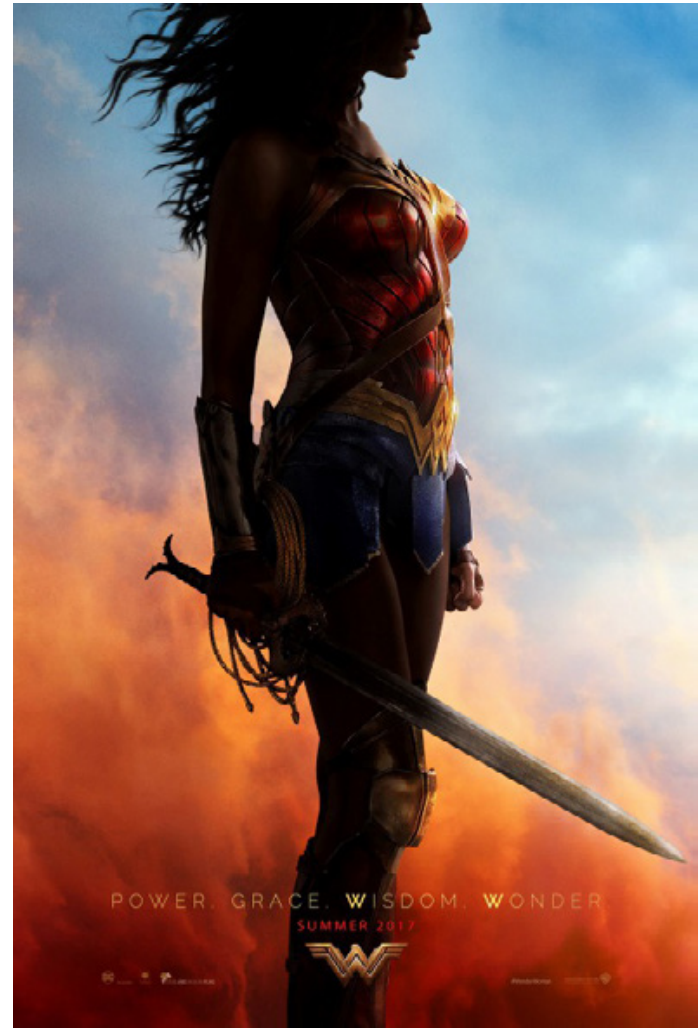

Fonte: https://whyilovemovies.com/home/2017/6/2/wonder-woman-2017 
O cartaz mostra, visualmente, uma mulher ao centro, segurando uma espada e com o rosto no escuro, cortado em sua parte superior, o que impede a identificação da pessoa. A mulher veste um traje vermelho, amarelo e azul, utiliza braceletes nos dois punhos e aparentemente uma bota até os joelhos. Ao fundo, aparece algo semelhante a uma fumaça, com as mesmas cores do uniforme da mulher. Os únicos signos verbais (com a entoação vocal subentendida, uma vez que o texto se encontra impresso) existentes são "Power. Grace. Wisdom. Wonder." [Poder. Elegância. Sabedoria. Maravilha, em tradução livre], e abaixo "Summer 2017", uma indicação de que o filme estrearia no verão de 2017. Não existe nada que indique o nome do filme, porém os elementos verbivocovisuais que compõem o enunciado (especialmente pela vestimenta como caracterização da personagem de rosto indefinido) nos levam a identificar que se trata do filme da MulherMaravilha, uma mulher misteriosa (uma vez que não podemos identificar sua identidade pelo corte de seu rosto e por seu corpo estar na sombra), guerreira (característica marcada pela espada e por sabermos que Diana passa a ser considerada, a partir do Arco Novos 52, deusa da guerra, filha de Zeus e Hipólita, logo, princesa das amazonas), prisioneira (característica marcada pelos braceletes, chamados de "braceletes da submissão", típicos das amazonas, anteriormente, escravas de Zeus) e pela roupa (caracterizada pelas cores da bandeira norte-americana).

A personagem é considerada por muitas pessoas um ícone de empoderamento feminino por ser uma amazona, semi-deusa, repleta de super-poderes. Todavia, esse empoderamento pode ser questionado pelas marcas de submissão de sua caracterização corpórea, marcada pelos acessórios braceletes (chamados "braceletes da submissão), laço (denominado "laço da verdade", usado em relações sadomasoquistas), escudo, tiara; e pelos traços volumosos de seu corpo, extremamente erótico/sexualizado, o que é criticado por muitas ativistas, de diversas associações e de muitos coletivos.

A adjetivação "maravilha" pode se referir tanto aos super-poderes dessa mulher-amazona, o que pode remeter à ideia de uma mulher empoderada, quanto à ideia de submissão, escravidão voluntária, masoquismo (isso aparece nas HQs desde o surgimento da MM de maneira bastante forte) e sexualização de um corpo padronizado compreendido como ideal e, nesse sentido, o adjetivo inculca valores machistas que confirmam padrões patriarcais de comportamento. Essa contradição constitui a MM.

Carol Danvers, a Capitã Marvel, por sua vez, criada no final dos anos 60, passa a ser nomeada por sua patente militar (capitã) e pela empresa que a cria (Marvel), perdendo sua identidade em 2012. Nesse momento, ela passa a ser uma das mais poderosas personagens da Marvel e ganha, depois do sucesso de MM, as telas do cinema, como protagonista da própria história (isso, em 2019) e da história da Marvel, simbolizando uma nova era, uma vez que os Vingadores e o Capitão América encerraram seus trabalhos. 
Em seu filme, que se passa na década de 1990, ela faz parte do exército do povo alienígena Kree, em que eles estão em guerra com outro povo alienígena, os Skrulls. A Capitã não consegue se lembrar de seu passado; em certo momento, ela acaba caindo na Terra (precisamente, nos Estados Unidos) e, aos poucos, lembra-se de que aquela era sua terra natal, de que ela era humana e agente da Força Aérea dos Estados Unidos da América. Ela foi atingida por uma explosão de um material alienígena e se tornou superpoderosa. Segue um dos cartazes de divulgação do filme.

Figura 2. Cartaz de divulgação do filme Capitã Marvel (2019)

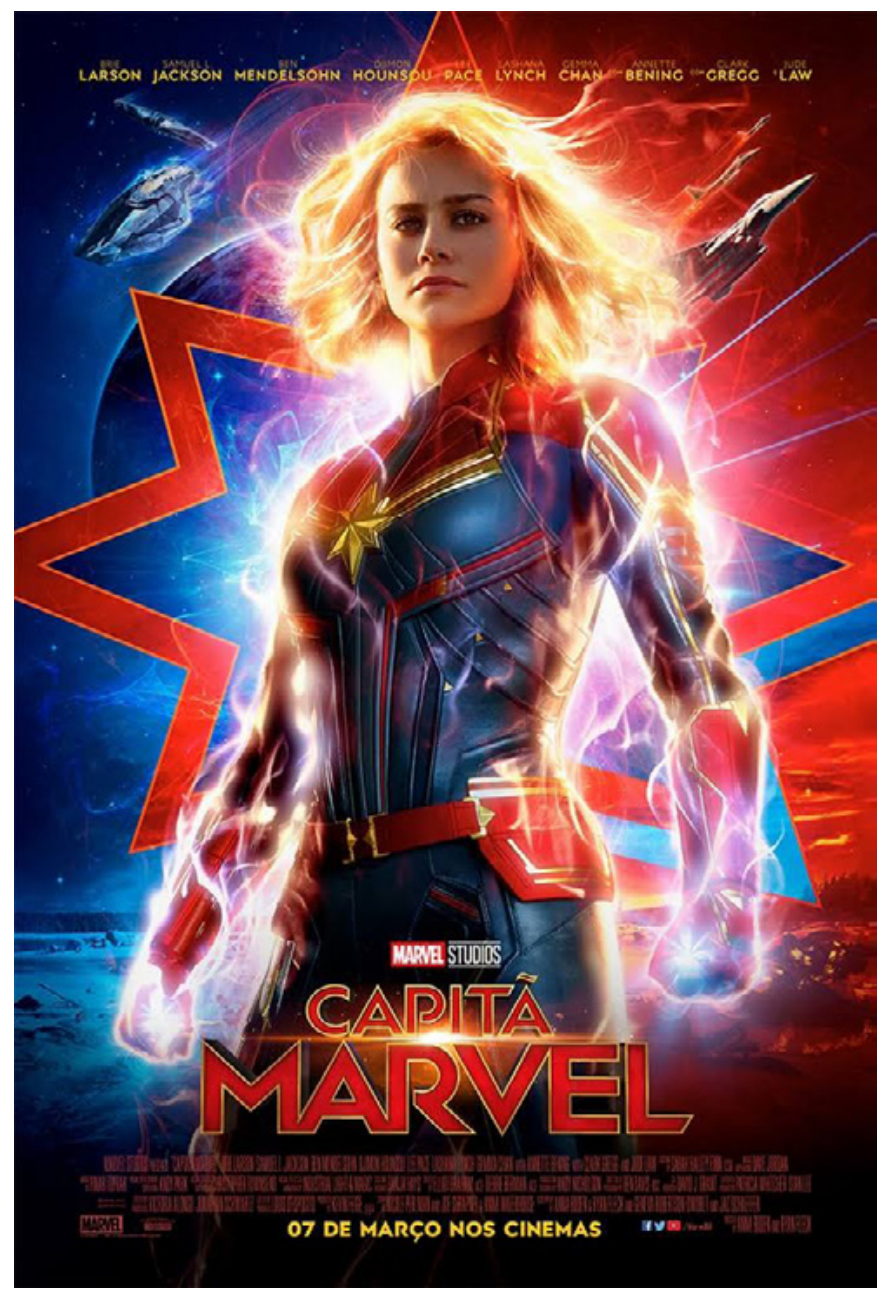

Fonte: https://bit.ly/2Mw4gpR

O cartaz se assemelha em vários aspectos com o da Mulher-Maravilha. Na dimensão visual, as cores predominantes são o vermelho e o azul; ao centro, está a protagonista do filme, que, dessa vez, não está no escuro, ao contrário, está iluminada e identificada. Ela usa um uniforme vermelho, azul e dourado; seus punhos estão cerrados e raios saem 
deles. O nome do filme aparece, verbo-vocalmente, na parte inferior do cartaz, assim como a data de estreia. A Capitã está de frente e encara o público (enquanto a MulherMaravilha está de perfil, sem que pudéssemos ver seu rosto).

O referido filme superou a bilheteria da Mulher-Maravilha, arrecadando cerca de 1.128 bilhão de dólares. Porém, mesmo tendo mais público no cinema do que a MM, a Capitã não conquistou o coração de muita gente, ainda que também seja considerada um ícone de empoderamento por lutar pela igualdade de gêneros, por seus super-poderes e, diferente da $\mathrm{MM}$, por não se submeter a nada nem a ninguém, aparentemente. A seguir, tentamos explicar o que acontece ao considerarmos as duas personagens e as valorações que representam, inclusive, fora das telas (já que consideramos aqui as obras fílmicas).

Com o surgimento do filme da Capitã Marvel, as comparações com a Mulher-Maravilha foram inevitáveis. Os próprios estúdios que produziram os filmes são concorrentes. Isso gerou muitas respostas da parte do público, uns defendendo a MM, outros a Capitã, como se realmente existisse uma disputa entre elas, que fazem parte de universos distintos. Observamos essas reações dos telespectadores através, principalmente, das redes sociais, nas quais o público explicitou suas opiniões de amor e ódio. Ao observarmos os produtos de consumo que são produzidos com a imagem das super-heroínas, percebemos uma notável diferença.

As capturas das imagens foram tiradas de uma pesquisa no Google Imagens com as frases: "produtos Mulher-Maravilha" e "produtos Capitã Marvel". O site não estava conectado com nenhuma conta, para que os resultados não fossem alterados. Na Figura 3, observamos que existe uma imensa variedade de produtos da MM, desde esmaltes, canecas, copos, até patins, utensílios de cozinha, guarda-chuva etc. Já na Figura 4, os resultados não são tão variados assim, pois vemos algumas canecas, bonecas, quadros, mas a maioria das imagens é da própria Capitã Marvel, não de seus produtos. 
Figura 3. Produtos da Mulher-Maravilha

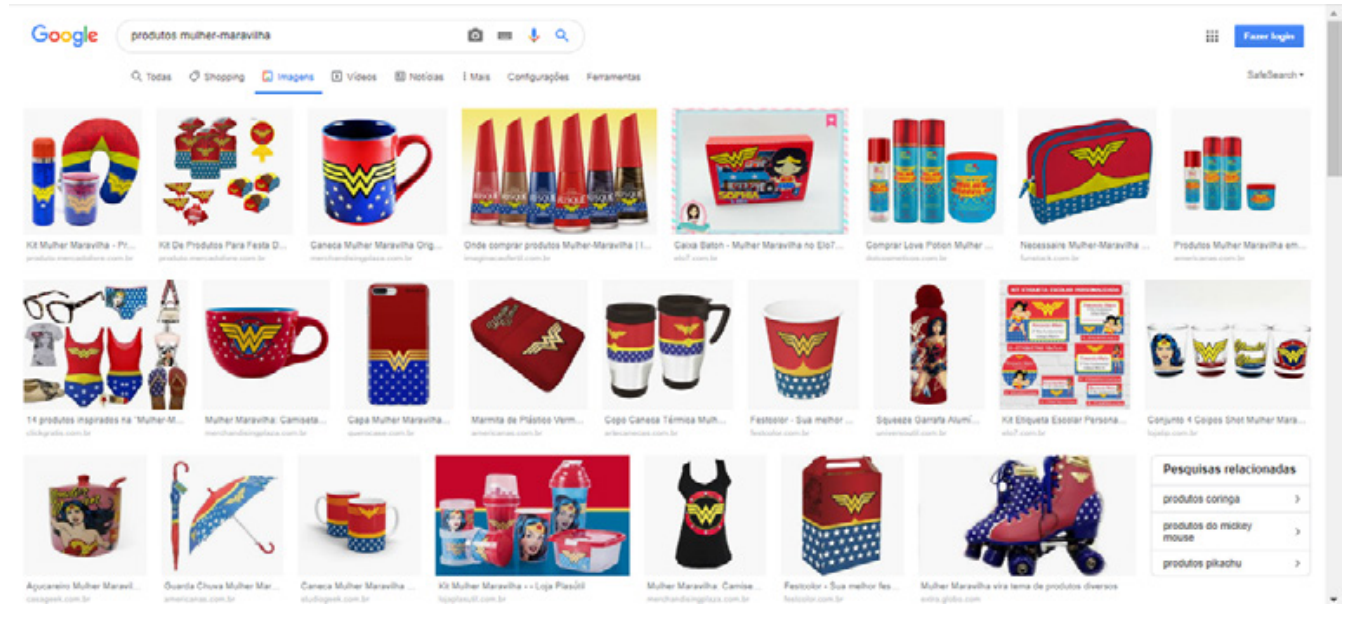

Fonte: https://bit.ly/2Udjvlx

Figura 4. Produtos da Capitã Marvel

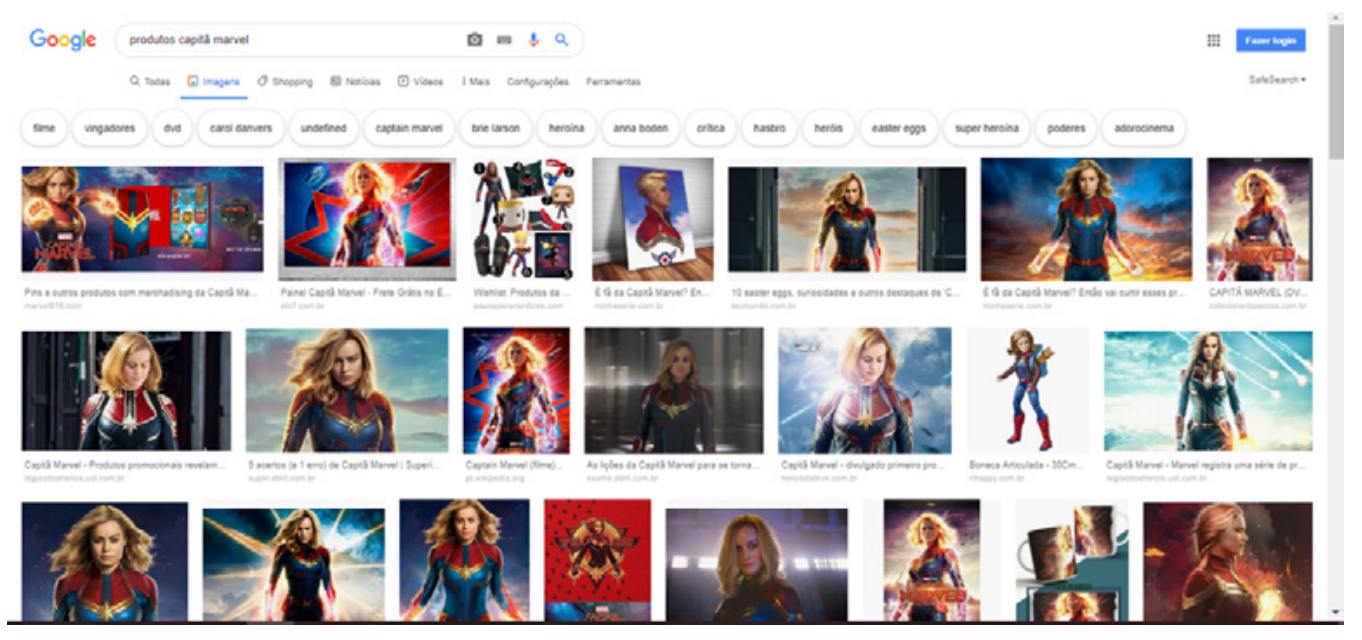

Fonte: https://bit.ly/2BCOmYv

Percebemos, pelas imagens, que a figura da Mulher-Maravilha é muito mais explorada/ comercializada do que a da Capitã Marvel, e se isso acontece é porque ela também vende mais, é mais rentável aos produtores do que a heroína da Marvel. Isso pode ocorrer pelo fato de a Capitã Marvel estar em evidência há menos tempo do que a Mulher-Maravilha, mas não podemos afirmar com precisão. De todo modo, sabemos que a CM vem sendo muito criticada pelo público desde sua estreia no cinema. Muitos não gostaram da escolha da atriz Brie Larson como intérprete da heroína por não a considerarem "bonita" ou "gostosa" o suficiente (o que nos remete à sexualização e à padronização do corpo da mulher como uma espécie de condição para que ela seja considerada uma super- 
heroína) ou por acharem que a personagem é muito "séria" e pouco simpática (o que remete ao valor de que uma mulher super-heroína deve ser sorridente, receptiva, gentil etc. para ser atraente).

A figura que segue mostra uma publicação no Facebook oficial da Marvel no Brasil com imagem e comentários (verbo-vocais) dos fãs/haters.

Figura 5. Publicação do Facebook sobre a Capitã Marvel

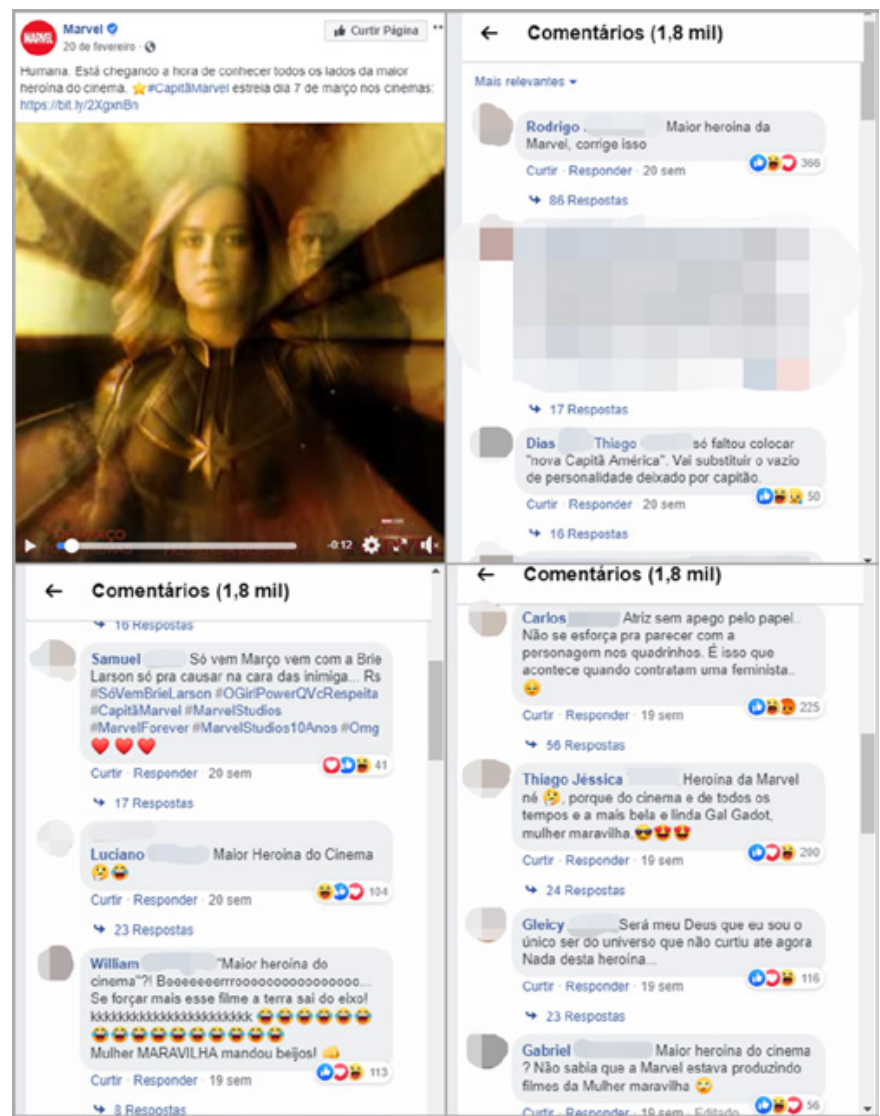

Fonte: https://bit.ly/306KnO2

A publicação foi criada em 20 de fevereiro de 2019, pouco antes de o filme estrear. Trata-se de um vídeo (enunciado materialmente verbivocovisual) de poucos segundos de apresentação da super-heroína. A legenda (verbal) da publicação é: "Humana. Está chegando a hora de conhecer todos os lados da maior heroína do cinema". O fato de ela ser humana ganha destaque, mas o de que ela é a maior heroína do cinema incomoda muito o público, em especial, o masculino (atentemo-nos para o fato de que a maioria maciça das postagens que criticam a atriz e a Marvel foi feita por homens, que colocam como "defeitos" da atriz o seu corpo e o fato de ser feminista). A publicação conta 
com cerca de mil e oitocentos comentários, os que ganham maior relevância são os que recebem um maior número de "reações", uma ferramenta do Facebook. A maioria é desfavorável ao filme e compara a Capitã Marvel com a Mulher-Maravilha, tal como esse, em tom de sarcasmo: "Maior Heroína do cinema? Não sabia que a Marvel estava produzindo os filmes da Mulher-Maravilha".

Se compararmos essa publicação com uma da MM, parecida em número de visualizações e comentários, veremos que não acontece a mesma coisa:

Figura 6. Publicação do Facebook sobre a Mulher-Maravilha

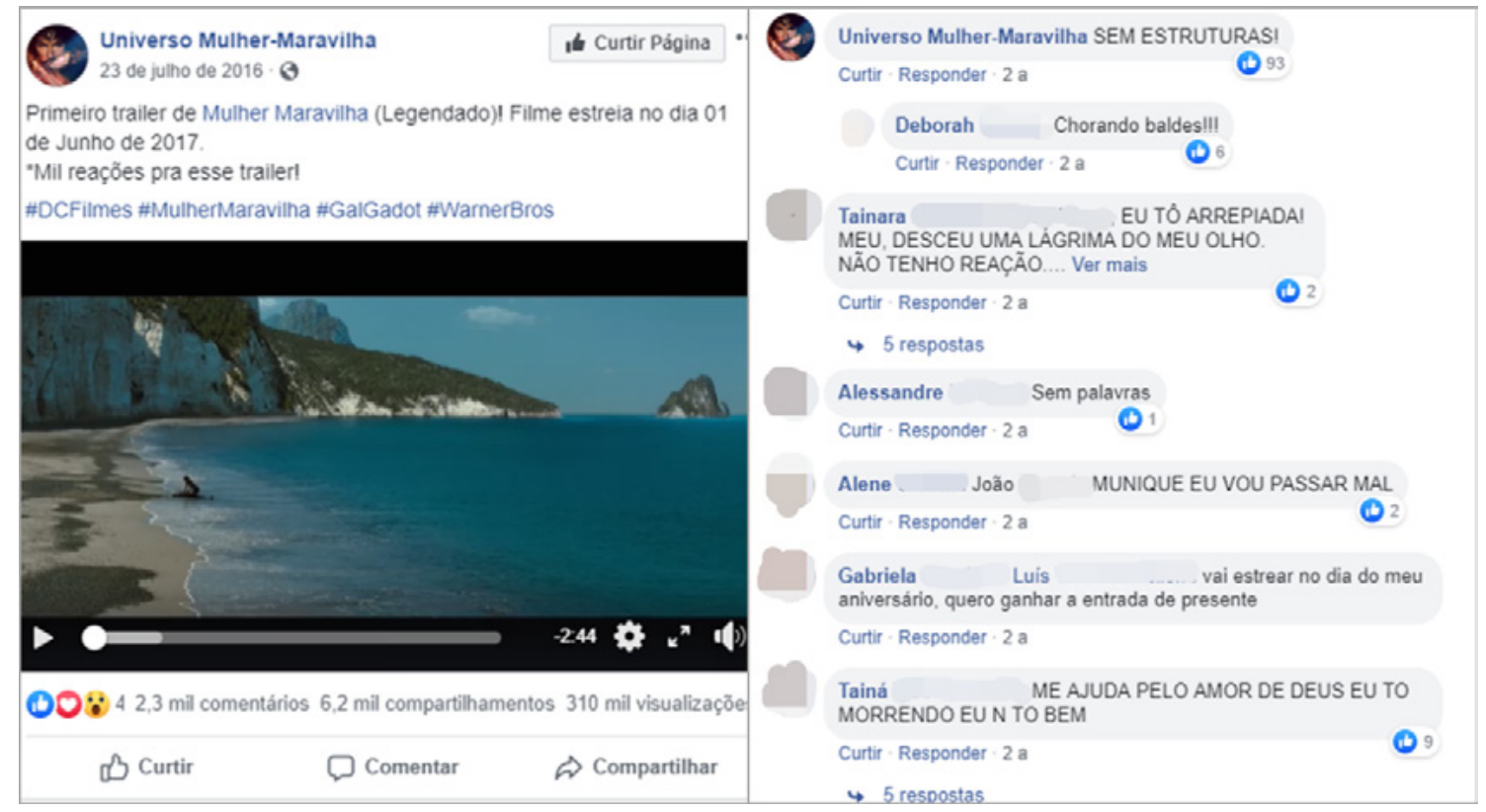

Fonte: https://bit.ly/30dlekS

O vídeo foi publicado pela página Universo Mulher-Maravilha, em 23 de julho de 2016 e divulga o primeiro trailer do filme. Os comentários, diferentemente dos anteriores, são todos de mulheres e elogiosos ao filme e à super-heroína. A impressão é de que a MulherMaravilha serve de inspiração para as mulheres, mas a Capitã Marvel não, mesmo ela sendo mais forte do que a heroína amazona, não ter deixado seu lar, família e amigas depois de ter conhecido um homem, como a Diana fez.

A questão amorosa, talvez, romantize e remeta a um padrão valorado positivamente ao longo da história, com animações de princesas e comédias românticas. Isso fica muito evidente quando pensamos no final do filme, em que MM desperta seu verdadeiro poder e derrota o inimigo quando vê seu amado morrer e, em seguida, se autoexila, escondendo 
sua identidade ao se sentir sem mais função, dada a morte de Trevor. De certa forma, isso confirma a ideia de que a super-heroína tem sua imagem de empoderamento atrelada à figura masculina. Esse arquétipo da mulher que deixa tudo, até mesmo seus poderes, para seguir um homem ainda é, mesmo hoje, na contemporaneidade, em pleno século $X X I$, muito forte. Se considerarmos a onda conversadora e tradicional que tem aplacado o mundo todo, então, isso fica ainda mais latente, em especial, advindo de discursos de instituições religiosas, que se colocam contrárias ao feminismo, à emancipação e ao empoderamento da mulher, tentando circunscrevê-la ao ambiente doméstico e à função de "primeira-dama", aquela que segue o homem, como faz a Mulher-Maravilha, colocando-se em segundo plano; jamais como protagonista da cena, como ocorre com a Capitã Marvel, que se rebela em nome de sua autonomia, voltada às suas raízes.

\section{Considerações finais}

Ao final desta pequena demonstração das respostas geradas pelos filmes MulherMaravilha (2017) e Capitã Marvel (2019), consideramos que a hipótese de que as superheroínas refletem e refratam vozes sociais sobre o que é ser mulher em nosso tempo e lugar históricos se confirma. As respostas mostram como existem posicionamentos diferentes sobre o mesmo signo ideológico, a depender, conforme ficou nítido pelos comentários, do gênero. As valorações acerca do que significa ser uma super-heroína ainda se confundem ou, no mínimo, remetem à ideia de princesa e se pautam em características que subjugam a mulher, reduzindo-a a seu corpo (sexualizado, erotizado, correspondente a determinado padrão de beleza) e comportamento (tipicamente dócil sorridente, receptivo, gentil, passivo).

Assim, o empoderamento de suas personalidades, marcado por seus super-poderes, fica em segundo plano ou passa a ser pretexto de reconfiguração de um modelo de mulher que permanece submisso ao homem, sem vida autônoma própria, pois um ícone de negação de seu ser e de sua história, especialmente ao que tange à Mulher-Maravilha que, muitas vezes, reforça estereótipos da "mulher ideal". Ela pode ser "poderosa", mas deve ser "elegante", é "sábia", mas sua "maravilha" está no corpo tão criticado e questionado pelo público masculino da Capitã Marvel, inclusive, com a competência da atriz sendo posta à prova com argumentos que nada têm a ver com a interpretação de seu papel, mas sim pelo fato de ser feminista. De fato, há uma mistura de valores que influencia na composição da valoração acerca do que é ser mulher.

Enquanto a MM deixa a ilha das amazonas para levar Steve Trevor de volta à Terra, em nome do amor, tanto por Steve, quanto pelos Estados Unidos; a Capitã Marvel não possui um par romântico (ao menos, não por enquanto). Ela não faz questão de parecer elegante e sexy, apenas deseja salvar o mundo de uma invasão alienígena. Seu uniforme é um macacão comprido nos braços e nas pernas, que mais parece uma armadura, enquanto o da Mulher-Maravilha é um bustiê vermelho apertado e uma minissaia. Os valores 
apresentados pela Capitã Marvel não são tão aceitáveis para o público (tanto masculino quanto feminino) como os da Mulher-Maravilha, de tal modo que, por isso, as mulheres se identificam e se autodefinem MMs ao invés de Capitãs. Efetivamente, ainda estamos diante do patriarcado com seus valores ressignificados.

A imagem da Mulher-Maravilha exerce maior influência sobre o comportamento das mulheres/meninas atuais (o que se expressa pelo número de produtos que recebem sua imagem). A Mulher-Maravilha existe desde 1941 e se tornou a maior super-heroína das HQs e do cinema. Por sua vez, a Capitã Marvel teve sua primeira aparição em 1968 e nunca alcançou tanta aceitação. Não podemos nos esquecer da função icônica dos super-heróis em geral, assim como o quanto dependem do mercado, como figuras massivas que são. Esses sujeitos femininos (MM e CM) são construídos e alterados na sua relação com o outro (fãs/haters), a partir do mercado e esse movimento é constante. As duas superheroínas continuarão a inspirar (ou não) milhares de mulheres e meninas pelo mundo e irão gerar muitas outras respostas na cadeia discursiva, de maneira ressignificada, com valorações ambivalentes e contraditórias.

As Mulheres-Maravilhas, hoje, são Capitãs Contemporâneas que aliam empoderamento, autonomia, independência e liberdade para terem o corpo que quiserem, fazer o que bem entenderem, com ou sem um par romântico, mas sempre acompanhadas de seus círculos de amizade (seja de super-heróis seja de humanos). Que nossas maravilhas sejam aquelas que quisermos, com liberdade de sermos o que e como for, sem patentes, com nomes/identidades e vozes próprias. Super-heroínas reais, cotidianamente em luta, sem precisar de modelos a serem seguidos. E que assim possamos ser vistas, sem julgamentos por nossos corpos ou comportamentos, aceitas como somos, como seres humanos que não precisam provar seu valor todo o tempo.

\section{REFERÊNCIAS}

BAKHTIN, M. M. (VOLÓCHINOV). Discurso na vida, discurso na arte. Mimeo (traduzido para fins acadêmicos da versão inglesa), sem referência.

BAKHTIN, M. M. Teoria do romance II: as formas do tempo e do cronotopo. Rio de Janeiro: 34, 2018.

BAKHTIN, M. M. Gêneros do discurso. São Paulo: 34, 2016.

BAKHTIN, M. M. Teoria do romance I: a estilística. Rio de Janeiro: 34, 2015.

BAKHTIN, M. M. Questões de estilística no ensino da língua. Rio de Janeiro: 34, 2012. 
BAKHTIN, M. M. Cultura popular na Idade Média e no Renascimento - o contexto de François Rabelais. São Paulo: Hucitec, 2010.

BAKHTIN, M. M. Para uma filosofia do ato responsável. São Carlos: Pedro \& João, 2009.

BAKHTIN, M. M. Estética da Criação Verbal. São Paulo: Martins Fontes, 2003.

BAKHTIN, M. M. Freudismo. São Paulo: Perspectiva, 2001.

BAKHTIN, M. M. Problemas da Poética de Dostoievski. São Paulo: Forense, 1997.

BAKHTIN, M. M. Questões de Literatura e de Estética. São Paulo: UNESP, 1993.

BRAIT, B. (org.). Bakhtin e o Círculo. São Paulo: Contexto, 2009a.

BRAIT, B. (org.). Bakhtin - Dialogismo e Polifonia. São Paulo: Contexto, 2009b.

BRAIT, B. (org.). Bakhtin: outros conceitos-chave. São Paulo: Contexto, 2007.

BRAIT, B. (org.). Bakhtin: conceitos-chave. São Paulo: Contexto, 2005.

BRAIT, B. (org.). Bakhtin, dialogismo e construção do sentido. Campinas: UNICAMP, 2001.

FARACO, C. A. Linguagem e diálogo: as ideias linguísticas do Círculo de Bakhtin. São Paulo: Parábola Editorial, 2009.

GERALDI, J. W. Sobre a questão do sujeito. In: PAULA, L. de; STAFUZZA, G. B. (org.). Círculo de Bakhtin: teoria inclassificável. Campinas: Mercado de Letras, 2010. p. 279-292.

MEDVIEDEV, P. N. Método formal nos estudos literários. São Paulo: Contexto, 2012.

PAULA, L. de. Verbivocovisualidade: uma abordagem bakhtiniana tridimensional da linguagem. Projeto de Pesquisa em andamento. UNESP, 2017 a.

PAULA, L. de. O enunciado verbivocovisual de animação - a valoração do "amor verdadeiro" Disney - uma análise de Frozen. In: FERNANDES JR., A.; STAFUZZA, G. B. (org.). Discursividades Contemporâneas - política, corpo e diálogo. Série Estudos da Linguagem. Campinas: Mercado de Letras, 2017b. p. 287-314. 
PAULA, L. de; FIGUEIREDO, M. H. de; PAULA, S. L. de. "O marxismo no/do Círculo de Bakhtin". In: PAULA, L. de; FIGUEIREDO, M. H. de; PAULA, S. L. de. Slovo - O Círculo de Bakhtin no contexto dos estudos discursivos. Curitiba: Appris, 2011. p. 79-98.

PAULA, L. de; OLIVEIRA, F. A. A. de. O signo "resistência" nas eleições presidenciais de 2018 no Brasil. Revista ENTRELETRAS (Araguaína), v. 10, n. 2, p. 350-371, jul./dez. 2019b.

PAULA, L. de; SERNI, Nicole Mioni. A vida na arte: a verbivocovisualidade do gênero filme musical. Raído, Dourados, v. 11, n. 25, p. 178-201, jul. 2017. Disponível em:

http://ojs.ufgd.edu.br/index.php/Raido/article/view/6507. Acesso em: 17 jul. 2017c.

PAULA, L. de; SILVA, T. N. Nerve à flor da linguagem: arte e vida em jogo dialógico. Diálogo das Letras, Pau dos Ferros, v. 8, n. 2, p. 38-57, maio/ago. 2019a.

PAULA, L. de; STAFUZZA, G. (org.). Círculo de Bakhtin: concepções em construção. v. 4, Série Bakhtin - Inclassificável. Campinas: Mercado de Letras, 2019.

PAULA, L. de; STAFUZZA, G. (org.). Círculo de Bakhtin: pensamento interacional. v. 3, Série Bakhtin - Inclassificável. Campinas: Mercado de Letras, 2013.

PAULA, L. de; STAFUZZA, G. (org.). Círculo de Bakhtin: diálogos in possíveis. v. 2, Série Bakhtin - Inclassificável. Campinas: Mercado de Letras, 2012.

PAULA, L. de; STAFUZZA, G. (org.). Círculo de Bakhtin: teoria inclassificável. v. 1, Bakhtin - Inclassificável. Campinas: Mercado de Letras, 2011.

VOLÓCHINOV, V. N. A construção da enunciação e outros ensaios. São Carlos: Pedro \& João, 2013.

VOLÓCHINOV, V. N. Marxismo e filosofia da linguagem: problemas fundamentais do método sociológico na ciência da linguagem. Rio de Janeiro: 34, 2017. 